Mavi Atlas, 5(2)/2017: 489-501. Araştırma Makalesi | Research Article

Makale Geliş | Received: 10.07.2017

Makale Kabul | Accepted: 15.08.2017

DOI: 10.18795/gumusmaviatlas.351357

Seda ÖZSOY

Yrd. Doç. Dr. | Assist. Prof. Dr. Gümüşhane Üniversitesi, Edebiyat Fakültesi, Felsefe Bölümü, Gümüşhane-Türkiye Gümüşhane University, Faculty of Letters, Department of Philosophy, Gümüşhane-Turkey

orcid.org/0000-0002-2473-4258 sedazsy@yahoo.com.tr

\title{
Hitit Döneminde İnşa Edilen Su Yapılarının Bilimin Tarihsel Gelişimi Açısından Değerlendirilmesi
}

$\ddot{O} \mathbf{z}$

Su, tüm canlılar için vazgeçilemez ve ikame edilemez olması itibariyle büyük bir öneme sahiptir. Mezkûr vazgeçilmezlik dolayımında medeniyetlerin ilk kurulduğu yerlerin su kenarlarında bulunması dikkate değerdir. Kadim felsefe geleneğinde de evrenin ilk ilkesinin su şeklinde kabul edilmesi, suyun, içinde her şeyin hayat bulduğu bir yapıya sahip olduğunun benimsenmesinden ileri gelir. İnsanlık tarihi boyunca suya yaşamsal niteliği haiz olmasının yanında manevi anlamda kutsallık atfedilmiş̧ir. Bu çalışmada, Hitit döneminde inşa edilen su yapılarının salt mimari ve dini açılardan değil, aynı zamanda bilim ve teknoloji tarihi açısından da ne ölçüde önemli görüldüğü ortaya konacaktır.

Anahtar Kelimeler: Su, Hititler, Su Yapıları.

\section{Evaluation of Water Bodies which Constructed in Hitit Period in Terms of Historical Development of Science}

\begin{abstract}
Water is essential and unsubstitutional for all living creatures. For that reason it is remarkable that the places where the civilizations were first established are also on the water's edge. In the tradition of old philosophy was accepted the first instance of the universe as water because everything energize in the water. Throughout human history people attributed holiness to the water. In this study, it is evaluated that water bodies which were constructed in Hittites term, are very important not only from architectural and religious but also scientific and technological aspects.
\end{abstract}

Keywords: Water, Hittites, Water Constructions. 


\section{Giriș}

İnsanın tarih öncesi dönemlerden başlayıp günümüze kadar uzanan serüveninin belirgin yönünü, doğayı tanıma ve onu kontrol altına alma güdüsü oluşturmaktadır. Bu güdüyle şekillenen davranışları ekseninde insan, uygarlaşmanın da ilk adımlarını atmıştır. Uygarlaşmanın başlangıcının ise insanın gereksinimlerine bağlı olarak büyük nehirlerin kıyısında gerçekleştiğini söylemek mümkündür. Bütün canlıların yaşamlarını sürdürebilmeleri için en temel gereksinim maddesi olan su, insanların yerleşme yerleri olarak seçtikleri coğrafyanın karakteristiğini meydana getirmiştir. Asya'da İndus ve Ganj, Afrika'da Nil, Kuzey Amerika'da Mississipi, Güney Amerika'da Amazon ve diğer birkaç büyük nehir, uygarlığın başlatıldığı ve devam ettirildiği alanlar olarak tarihte yerlerini almışlardır. Buna koşut olarak insan yaşamı için en elverişli yerleşim bölgelerinden biri de Anadolu olmuştur. Farklı coğrafyalardan göç alan ve "uygarlığın beşiği" olarak nitelenen Anadolu; Hitit, Urartu, Frig ve Lidya Uygarlıklarına ev sahipliği yapmıştır.

Bilindiği üzere Anadolu topraklarının gelişmesine katkı sağlayan önemli yerleşimcilerden biri Hititlerdir. MÖ 2000 dolaylarında Anadolu'da yaşam alanları kurmaya başlayan Hititler, tarım ve hayvancılığa dayanan ekonomileriyle gelişmiş bir siyasi yap1 oluşturmayı başarmışlardır. Siyasal iktidarın dinsel unsurlar üzerine temellendiği bir düzeni temsil eden Hititler, kentlerini ve tapınaklarını salt yaşamsal önemi dolayısıyla değil, aynı zamanda dini açıdan da değer arz eden su kaynaklarının yakınlarına kurmuşlardır. Bu doğrultuda Hititler, Anadolu'da karşımıza çıkan ilk su yapılarını meydana getirmişlerdir çünkü su, yaşamanın olduğu kadar arınmanın da ilk şartıdır. Bu çalışmada, Anadolu'da önemli bir konuma sahip olan Hitit Uygarlığının kurmayı başardığı baraj, su toplama havuzu ve su anıtları gibi su yapıları incelenmeye çalışılacaktır. Buradaki temel amaç, Hititlerin yaşadıkları koşullar ekseninde bilim, teknoloji ve mühendislik alanlarında hangi düzeyde olduklarının, böylece Anadolu'nun farklı kültürler aracılığıyla nasıl şekillendiğinin ve bu coğrafyada yaşamış olan toplulukların bıraktığı mirasın neler olduğunun ortaya konmasıdır. 


\section{Hitit Uygarlığı Üzerine Kısa Bir Değerlendirme}

Konunun bağlamı açısından Anadolu'nun o yıllardaki durumunun ve Hitit Devleti'nin başlangıcından itibaren nasıl yapılandığının kısaca serimlenmesi faydalı olacaktır. Tarihsel gelişim seyri açısından konuya yaklaşıldığında Antik Dönem boyunca Anadolu'nun pek çok farklı coğrafyadan göç alan bir bölge olduğu belirginlik kazanır. Akad kaynaklarına Anadolu'nun Hatti Ülkesi olarak geçmesinde etken olan ve MÖ 2500 ile 1700 yılları arasında burada yaşayan Hattiler, MÖ 3000 yılının sonlarında buraya yerleşen Hurriler, MÖ 2300 civarında Balkanlardan gelen Luviler, yine aynı dönemde Kuzey Anadolu'ya yerleşen Palalar ve Sinop yakınlarında yaşadıkları dışında haklarında detaylı bilgi olmayan Kaşkalar bölgenin ilk yerleşimcileridir. Hititlerin yazılı metinlerinden elde edilen bilgilere göre MÖ 2000 yılında Anadolu'da, bu topluluklar dışında varlık gösteren başkaları da mevcuttur. Bunlar; Arzawa, Willusa, MiraKuwaliya, Appawiya, Walma, Zippasla-Hariati, Karsika, Lukka, Masa, Ahhiyawa ve Seha Nehri ülkeleridir. ${ }^{1}$ Bu nedenle MÖ 2000 dolaylarında buraya gelen Hititlerin, bölgede daha önce yaşamaya başlayan bu topluluklarla karşıllaştığı ve bunlarla kaynaşarak bir uygarlık oluşturduğu söylenebilir. Anadolu'ya nereden göç ettikleri tam olarak bilinmeyen Hititlerin, Hint-Avrupa kökenli bir kavim olduğu ileri sürülmektedir. Burada henüz yazı kullanılmadığından konuya ilişkin üretilen tezler, arkeolojik bulgulara dayanmaktadır. Ancak bu halkın, Anadolu'ya ticari faaliyetler aracılığıyla yazı dâhil birçok kültürel unsurun aktarılmasında etkin olan Asur Ticaret Kolonileri döneminde burada yaşadığı kabul edilmektedir. Kızılırmak'ın güneyinde Kaniş ya da Neşa adı verilen bölgede ilk yerleşimlerini kuran Hititler, Hatti topraklarını ele geçirerek yayılmaya çalışmışlardır. Kaniş’te yapılan kazılarda, Asur kolonileri dönemindeki Anadolu'nun mimari yapısını yansıtan ve karum adı verilen ticaret merkezleri ile vabartum olarak bilinen kervansaraylar bulunmuştur. Böylece ticari faaliyetler ve kültürel etkileşim ekseninde şekillenen coğrafyada, Çorum ilinin

\footnotetext{
${ }^{1}$ Konuya ilişkin ayrıntılı bilgi için bkz.: KINAL, Füruzan (1991). Eski Anadolu Tarihi, Ankara: Türk Tarih Kurumu Yayınları.
} 
güneyinde yer alan Hattuşaş'1 başkent olarak belirleyen beylikler tarafından Hitit Devleti'nin temelleri atılmıştır (Akurgal 2005: 53; De Martino 2003: 31-76). ${ }^{2}$

Anadolu'nun çok parçalı yapısının içinde Hititlerden önce de siyasi birliği sağlama ve merkezi bir devlet oluşturma girişimleri olmuştur. Kuşşara kralı Pithana (MÖ yaklaşık 18. yüzyıl) ve oğlu Anitta, Orta Anadolu'daki şehirleri ele geçirerek Kaniş’i başkent yapmıştır. Pithana hakkındaki bilgiler kendisinden sonra kral olan oğlu Anitta'nın kaleme aldığı metinlerde yer almıştır. Başarılarından dolayı Rubaum Rabum (Krallar Kralı) olarak bilinen Anitta, birçok isyanı bastırmış ve giderek güçlenmiştir (Alp 2001: 58). Hititlerin ataları olarak gördükleri Anitta ve Kuşşaralılardan sonra başkenti Hattuşaş'a taşıyan Hattuşili I, MÖ 1650 ile 1620 yılları arasında devletin kralı olmuştur. Hattuşili I, ülke topraklarının genişletilmesinin yanında kültürel olarak gelişmenin de önünü açmıştır. Böylece koloni dönemindeki kültürel unsurlarla diğer Anadolu toplumlarının kültürünün bir sentezi olarak şekillenen Hitit kültürü; çoktanrılı dini yapısı, anıtsal mimari tarzı, çiviyazısı ve hiyeroglif yazısıyla dönemin özgün örneklerinden biri haline gelmiştir. $\mathrm{Bu}$ dönemin koşulları hakkındaki bilgiler ise Hattuşili I'in vasiyetnamesinde ve Eski Krallık Dönemi'ni anlatan Telepinus Fermanı'nda aktarılmıştır. Hattuşili I'in ölümünden sonra yerine torunu Murşili I geçmiş ve MÖ 1620 ile 1590 arasındaki dönemde devleti yönetmiştir. Kuzey Suriye'deki Halep Krallığı'nı yıkan Murşili I, o zamanların en önemli kültür merkezleri olan Mari ve Babil'i zapt ederek MÖ 1550'de I. Babil Sülalesine son vermiş ancak bir suikast sonucu hayatını kaybetmiştir. Kralın ölümünün ardından MÖ 1590 ile 1525 yılları arasında taht kavgalarıyla geçen bir kaos dönemi yaşanmıştır. Burada belirtilmesi gereken diğer bir önemli nokta da tavananna (ana kraliçe) adı verilen kraliçelerin ülke yönetiminde etkili olduğudur. Kral olmadığı zamanlarda onun yerine vekâlet eden, kralların mühürlerine adları yazılan ve kralın başrahip olmasından dolayı kendisi de başrahibe olan tavanannalar da taht kavgalarına müdahil olmuştur (Akurgal 2005: 118).

\footnotetext{
${ }^{2}$ Ayrıca konuya ilişkin ayrıntılı bilgi için bkz.: MACQUEEN, J. G. (2001). Hititler ve Hitit Çă̆ında Anadolu, çev. Esra Davutoğlu, Ankara: Arkadaş Yayıncılık, ss. 39-57; GURNEY, Oliver Robert (2001). Hititler, çev. Pınar Arpaçay, Ankara: Dost Kitabevi Yayınları, ss. 25-56.
} 
Eski Krallık Dönemi'nin MÖ 1525 ile 1510 arasındaki son kralı, Telepinus’tur. Telepinus Fermanı ile tanınan kral, yönetimi devralacakların soy esasına dayalı olarak seçilmesini öngören veraset yasalarını hazırlamış, taht mücadelelerine son vermeye ve ülke sınırlarını güvence altına almaya çalışmıştır. Ölümünün ardından ise yine taht kavgaları devam etmiş ve siyasi karışıklıklar artmıştır. Bu yıllarda yaşananlar ve Tuthaliya I'in MÖ 1400'lerde tahta çıktığı zamana kadarki sürece ilişkin bilgiler oldukça sınırlıdır ancak bu kralla birlikte Hitit Devleti'nin yeni bir döneme girdiği söylenebilir (Ponting 2011: 149). Bu yüzyılda Tuthaliya II, Arnuwanda I ve Tuthaliya III'ün mensup olduğu hanedan yönetimde etkin oluncaya kadar devlet, önemli ölçüde güç kaybetmiş durumdadır. Hitit'in etkisinin azalmasından faydalanan Hurriler, Mitanni Devleti'ni kurmuştur. Takip eden yıllarda hanedanın yönetiminde Hititler, yeniden canlanmaya ve kaybettikleri toprakları geri almaya başlamıştır. Tuthaliya II (MÖ 14601440), ülkenin yakın doğudaki çıkarlarını korumayı başarmış ve yazılı kaynaklarda Hattuşili I, Murşili I ve Şuppiluliuma I gibi en önemli dört Hitit kralından biri olarak yer almıştır. Tuthaliya II'den sonra Hurrilerle iyi ilişkiler kurmaya çalışan Arnuwanda I (MÖ 1440-1420) ve kuzeyde Kaşka, güneyde Arzawa ile güneydoğuda Halep krallıklarına karşı ülkesini savunan Tuthaliya III (MÖ 1400-1381) krallık yapmıştır. Ardından Hititlerin en güçlü ordu komutanı ve en başarılı devlet adamı olarak kabul edilen Şuppiluliuma I (MÖ 1380-1345) göreve gelmiştir. Kargamış ve Halep'i ele geçirerek oğullarının yönetimine veren kral, Mitanni ve Amurrular ile dostluk kurmuş ve sonunda Hurri ülkesini yenmiştir (Akurgal 2005: 69-80). Şuppiluliuma I'in veba salgınında ölmesinden sonra sırayla Arnuwanda II (MÖ 1346-1345), Murşili II (MÖ 1345-1315), Mutavalli (MÖ 1315-1282), Murşili III (MÖ 1282-1275), Hattuşili III (MÖ 1275-1250), Tuthaliya IV (MÖ 1250-1220), Arnuwanda III (MÖ 1220-1200) ve Şuppiluliuma II (MÖ 1200-1190) kral olmuştur.

Hitit tarihinin en önemli olaylarından biri olan Kadeş Savaşı, bu krallardan Mutavalli döneminde yaşanmıştır. Hititlerin hüküm sürdügü yıllarda mücadele etmek zorunda kaldıkları sorunların başında Kaşkalar ve Mısırlılar ile yaşadıkları dış ilişskiler gelir. Kaşkalar, sürekli olarak Hitit topraklarına saldırmışlar, Mısırlılar ise Hitit 
Devleti'nin egemenliğinde bulunan Suriye'yi ele geçirmek istemişlerdir. Başkenti Hattuşaş’tan Adana civarındaki Dattaşa'ya taşıyarak mücadele stratejisi geliştiren Mutavalli, MÖ 1285 dolaylarında Mısır ile Kadeş Savaşı'na girmiştir. Mısır hükümdarı Ramses II’nin (MÖ 1290-1224) komutasındaki orduyla karşılaşan Hitit ordusu arasında yaşanan savaş, iki taraf için de ağır kayıplara neden olmuştur. Bunların üstesinden gelebilmek için krallığg zamanında Hattuşili III ise Mısır ile o güne kadar geciken Kadeş Antlaşması'nı imzalamıştır. İnsanlık tarihinin ilk yazılı antlaşması şeklinde kayıtlara geçen antlaşma ile iki ülke arasında savaş yapılmaması ve yardımlaşmaya dayalı iyi ilişkiler geliştirilmesi yönünde kararlar alınmıştır. Yaşanan sürecin ardından kral Şuppiluliuma II döneminde, Hitit Devleti sonuna yaklaşmıştır. MÖ 1200’lerde Ege Göçleri adıyla bilinen göç dalgası, Anadolu topraklarının büyük ölçüde tahrip edilmesine neden olmuş ve Anadolu'da güçlü bir yönetim kuran Hititlerin çöküşünü getirmiştir. Ancak MÖ 1200’den 650 yılına kadar Güneydoğu Anadolu ve Kuzey Mezopotamya'da Hitit kültürünü sürdüren küçük krallıklar (Geç Hitit Devletleri) oluşturulmuştur (Akurgal 2005: 195; Ponting 2011: 150-151).

Hint-Avrupa dil grubunun çeşitli lehçelerinin konuşulduğu Hitit Uygarlığı, tarım ve hayvancılığa dayanan ekonomisiyle gelişmiş bir siyasi yapı kurmayı başarmış ve tabarna unvanı alan kralların, tavannana olarak bilinen kraliçelerin ve soylulardan oluşan Pankuş (ya da Panku) meclisinin yönetiminde feodal bir devlet olarak hüküm sürmüştür. Ülke topraklarının geniş olması nedeniyle var olan farklı dini inançlara karşı oldukça hoşgörülü bir ortam oluşmuş ve daha sonra Helen ile Roma Uygarlıklarında karşılaşacağımız sinkretik yani birçok dinin kaynaşmasıyla şekillenen çoktanrılı bir inanç sistemi meydana getirilmiştir. Diğer uygarlıklar tarafından devam ettirilen bu sistem dolayısıyla Anadolu toprakları Bin Tanrı İli olarak anılmıştır. Hititler, dinin yanı sıra Hatti, Hurri ve Mezopotamya etkisi görülen bir mitolojiye de sahiptir ve bu mitolojik unsurlar ekseninde kyklop adı verilen, çok büyük taşlardan oluşan mimari eserler inşa etmişler, sanatsal açıdan önemli olan tanrı ve tanrıça heykelcikleri yapmışlardır. $\mathrm{Bu}$ dinsel ve mitolojik esinlemeler, kültürel unsurlar kadar mimari çalışmaların da şekillenmesinde etkili olmuş ve pek çok yapı, dini referanslar 
çerçevesinde inşa edilmiştir. Benzer bir yaklaşım tarzı suyla ilgili yapıların meydana getirilmesi noktasında da karşımıza çıkmaktadır.

\section{Hitit Uygarlığında Su Yapıları ve Bunların Bilim Tarihi Açısından}

\section{Önemi}

Hititler açısından su, salt fiziksel gereksinimlerin giderilmesi için değil, aynı zamanda dini ritüellerin de önemli bir parçası olarak kullanılmıştır. Çoktanrılı inanç sistemi ekseninde, her bir tanrıyı sunulan kurbanlar ve dinsel şölenlerle memnun etmenin yanı sıra tanrıların gazabından korunmak için arınmanın sağlanması da değer arz etmiştir. Arınmanın ön koşulu ise tanrıların huzuruna çıkarken bedensel yönden temizlenmiş olmaktır. Su kültü bağlamında bedenin, yaşanılan yerin, kullanılan eşyaların temizlenmesi için başat unsur olan su, kutsal olarak kabul edilmiş ve buna koşutlukla tapınakların yanına kutsal havuzlar inşa edilmiştir. Sadece yaşam alanları değil, tapınaklar da kutsal kabul edilen nehirlerin yanına kurulmuştur. Ayrıca her coğrafyada görülen kıtlık ve kuraklık tehlikesine karşı günlük kullanımın ve dini amaçların dışında suyun saklanmasını sağlayacak depolar, havuzlar, sarnıçlar, kanallar, pınar odaları ve barajlar yapılmıştır. Böylece suyun, hem Hititlerin yaşadığı bölgenin şekillenmesi adına işlev üstlendiğini hem de uygarlığın değerler sistemi içinde önemli bir konumda bulunduğunu söylemek mümkündür. Örf ve adetler, hukuk ve din anlayış1 suyun değerine ilişkin hükümlerle tesis edilmiştir.

Bunun en belirgin örneklerinden biri su ordalidir. Hititlerden önce de Anadolu ve Mezopotamya'da geçerliliğini koruyan prosedürlerden biri olan su ordali, bir tür yargılama tarzına işaret eder. Kişinin işlediği suçun tespitiyle gerekli görülen cezanın uygulanması aşamasında suçlunun suya atılarak infazın gerçekleştirildiği bir yöntem söz konusudur. Eğer suya atılan bir kişi, sudan çıkmayı başarırsa suçsuzluğunu kanıtlamış olur ancak bunu başaramazsa tanrıların onu aldığı kabul edilirdi. Hitit hukukunda yer alan "Kral bir konuda kızdırılırsa bütün mutfak personeli nehre girecek. Kim suçsuz ise kralın görevinde kalacaktır. Fakat kim suçlu bulunursa ben, büyük kral onu 
istemeyeceğim. O eşi, karısı ve çocuklarıyla ölüm cezasına çarptırılacak.” (Süel 2012: 311) şeklindeki hüküm, cezanın nasıl uygulandığı ile ilgili veriler sunar. Aslen hukuk kurallarının yazılı hale getirilmesinden önce teamül doğrultusunda işletilen bu yapı, suçlunun tüm ailesiyle birlikte cezalandırılacağını da karara bağlamıştır. Diğer yandan tanrılar tarafından cezalandırılmamak için arınmanın sağlanması adına kullanılan su, inanç sisteminin de bileşenlerinden biridir. Su kültü bağlamında ağız temizleme, tövbe etme, bedensel ve ruhsal arınma gibi unusrların Hititlerin önemli yerleşim merkezlerinden olan Şapinuva (Ortaköy-Çorum) kökenli olduğu bilinmektedir. Şapinuva'da ortaya çıkan ve buradan tüm Hitit Uygarlığına yayılan ritüeller, itkalzi ve itkahi kutsal metinlerinin okunmasıyla başlar, ardından tanrılar için kurban sunulur ve kurban sunan kişi, rahipler tarafından yıkanır (Murat 2012: 127-128). Böylece ruh ve beden arındırılır ve kutsallık atfedilen su, önemli bir işlevi yerine getirmiş olur.

Su ordali ve su kültü, Hitit Uygarlığı için hukuki ve dini açılardan suyun nasıl değerli olduğunu ispatlayan ritüelleri ve normları kapsar. Bunlar, toplumsal yaşamın düzenlenmesinde rol üstlendikleri kadar gündelik hayata yönelik gereksinimlerin karşılanmasına yardımcı olan baraj, su toplama havuzu, kanallar ve su anıtları gibi su yapılarının meydana getirilmesini sağlamışlardır. $\mathrm{Bu}$ eksende bilimin gelişim seyri içinde ele alındığında su yapılarının bu toplumun ilerleme düzeyi hakkında önemli veriler barındırdığı daha görünür olacaktır. Bunun en belirgin nedeni, talebi süreklilik arz eden suyun, yaşamın her alanında mevcut öneminin yanında bilim ve teknolojinin gündelik pratikler üzerinden nasıl yapılandığını da ortaya koymasından ileri gelmektedir. Esasen su yapılarında gözlemlenen ileri düzey -tarihsel koşullar bağlamında değerlendirildiğinde dönemin su yapılarının mühendislik bilgisi bakımından oldukça ileri bir düzeye işaret ettiği açıktır-, edinilen bilgilerin bilimsel ve teknolojik olarak nasıl sistemleştirildiğinin göstergesidir. Bu doğrultuda Hitit kentlerinde suyun kullanılması ve saklanması yönünde oluşturulan yapıların, su yönetimi konusunda ortaya çıkan gelişmelerin bir ürünü olduğunu söylemek yerinde olacaktır. Kentlerde, kayalıkların içine fiçı biçiminde oyulmuş sarnıçlar, yağmur sularının toplanmasını ve dağıtılmasını sağlamıştır. Genellikle tapınak kenarlarına inşa edildiği görülen havuzlar 
da suyun toplanması ve aynı zamanda dini törenlerin gerçekleştirilmesi işlevlerini yerine getirmişlerdir. Tapınaklara ve evlere su tedarikiyle ilişkilendirilen pınar odaları ve pis suları atıp temiz suları biriktiren su tekneleri dikkate değer yapılardır.

Yapılan kazılar sonucunda ulaşılan tabletlerden edinilen bilgiler 1şı̆̆ında, Hititlerin suyla ilgili yapılar inşa etme konusunda başarılı oldukları belirginlik kazanmaktadır. Bu bölgede -özellikle Çorum iline bağlı Alaca Höyük civarında1930’lu yıllardan itibaren Prof. Dr. Remzi Oğuz Arık, Prof. Dr. Aykut Çınaroğlu, Dr. Hamit Zübeyr Koşay ve Mahmut Akok yönetiminde gerçekleştirilen kazılarda, bu yapılar hakkında önemli bulgulara ulaşılmıştır. Bölge ve iklim şartlarına uygun olarak oluşturulan bu yapılar, Hititlerin altyapı çalışmalarını önemsediklerini göstermektedir. Suyu saklamak amacıyla yapılan depoların yanında, buralardan yaşam alanlarına suyu taşımak için kullanılan kanallar da dikkate değerdir. Depolardan alınan suyu pişmiş topraktan yapılmış silindir şeklindeki borularla evlere taşıyan kanallar, o dönemin bilim ve teknolojisi hakkında veriler sunmaktadır. Ayrıca buraların pisliklerden korunması, yılda en az bir kez temizlenmesi, sulama sisteminin bozulmasına sebep olanların cezalandırılması gibi konularla ilgili çeşitli belgelerden edinilen bilgiler, Hititler için su sisteminin önemini göstermektedir (İnal 2009: 17).

$\mathrm{Bu}$ yapıların en güzel örneklerinden biri olan barajlar, günümüze kadar sağlam kalabilmiştir. Bunlar; Çorum Alaca Höyük’teki Gölpınar, Kayseri Pınarbaşı yakınlarındaki Karakuyu, Konya Kadınhanı'ndaki Köylütolu, Beyşehir'deki Eflatunpınar ve Yalburt Yaylası civarındaki barajlardır. Ancak Eflatunpınar ve Yalburt örnekleri, barajdan çok su toplama işlevini yerine getiren birer havuz olarak da kabul edilmektedir. Bunlardan en bilineni olan ve Hitit kralı Tuthaliya IV zamanında inşa edildiği belirlenen Alaca Höyük Gölpınar Hitit Barajı'nın taş dolgu setinin yüzeyden yüksekliğgi yaklaşık $2 \mathrm{~m}$ 'dir ve bendin taşları yumruk büyüklügündedir. Alt kısımlarındaki taşları daha büyük olan baraj, killi toprakla takviye edilmiş ve böylece geçirgenliği önlenmiştir. Taşlarının arasında harç bulunmayan ve kille desteklenen barajın doğu batı yönündeki genişliği 15 m’dir. Barajın iki yanında bugün halen birinin işlevini sürdürdüğü iki adet savak bulunmaktadır. Savağın içinden gelen su, setin 
üzerinde $1 \mathrm{~m}$ seviye farkı ile iki ayrı kanala girmektedir. Uzunluğu yaklaşık $130 \mathrm{~m}$ olan taş setin ortasında bir depolama havuzu vardır. Tabanı kille kaplı olan bu havuzun genişliği ise 8 m civarındadır (Çınaroğlu \& Genç 2005: 265-276; Çınaroğlu \& Çelik 2006: 1-6). Yaklaşık 3250 yıllık olduğu tahmin edilen Alaca Höyük Gölpınar Hitit Barajı, bugün yeniden kullanıma açılmıştır.

Hitit döneminde yapılan Kayseri Pınarbaşı civarındaki Karakuyu Barajı ise Seyhan nehrinin bir kolu olan Zamantı nehrini oluşturan küçük bir dere üzerinde bulunmakta ve bu barajın, yine Hitit kralı Tuthaliya IV tarafından yaptırıldığı kabul edilmektedir. Dikdörtgen göl alanı üzerindeki baraj U şeklindedir. Dolu olan savağı kuzeyinde yer alan barajın inşa ediliş biçiminin bugünkü mühendislik prensiplerine uyduğu belirtilmiştir. Barajın kuzey kısmında bir dip savak izine rastlanmamış, su çıkışı üst savaktan yapılmış, bu da kanalın başında bulunan ahşap kondivi (su iletimini sağlayan dairesel yap1) bir sistemle çıkışın sağlandığı görüşlerini gündeme getirmiştir (Bildirici 2008: 21-28). Görüldüğü üzere bugün halen kullanımı sürdürülen örnekleriyle Hitit döneminde inşa edilen su yapıları, bilimsel ve teknolojik anlamda elde edilen gelişmişlik düzeyini ortaya çıkarmaktadır.

Benzer şekilde Konya ili Kadınhanı-Ilgın karayolunun ortalarındaki Köylütolu köyünde Hitit dönemine ait bir su toplama yapısının kalıntıları tespit edilmiştir. Mevsimlik yağışlar ve Mahmuthisar deresinden taşan sularla dolan bu baraj, Anadolu'nun en eski ve büyük barajlarındandır (Bildirici 2008: 23-24). Bu coğrafyadaki ilk su yapıları olma özelliğini taşıyan bu barajların dışında pek çok yapı bulunmuştur. Konya iline bağlı Beyşehir ilçesinde karşımıza çıkan Eflatunpınar Hitit Su Anıtı bunlardan biridir. Birbirine uygun taş blokların birleştirilmesiyle meydana getirilen yapı, özgün taş işçiliği ve kayaları üzerindeki kabartmalarıyla bir açık hava tapınağı görünümündedir. Dikdörtgen olarak tasarlanmış havuzu ve onun içindeki su kanalları ile bu anıt, Hititlerin sanatsal unsurları da kullandıkları mimari anlayışlarını ve bugün bile sağlamlığını koruması dolayısıyla teknoloji ve mühendislik bilgilerini gözler önüne sermektedir. 
Bu örneklerden biri de Yalburt Hitit Havuzu'dur. Konya'da bir pınarın suyunu toplamak için 105,40 $\mathrm{m}^{2}$ boyutunda inşa edilen bu havuzun dinsel ritüelleri gerçekleştirmek amacıyla tasarlandığı tahmin edilmektedir. Üzerinde hiyeroglif yazılar bulunan 22 taş bloktan oluşan havuzda, Tuthaliya IV'ün adının yazılı olduğu ve kanatlı güneş simgesinin resmedildiği bloklar olmasından dolayı bunun Tuthaliya IV zamanında yapıldığı kabul görmektedir (Bildirici 2008: 24). Bu civarda yüksek hacimde fışkıran bir kaynak bulunması nedeniyle havuzun buraya inşa edildiği ve bu doğrultuda buranın bir kaynak tapınağı olduğu görüşleri yaygınlaşmıştır. Konya ilinde bulunan bir başka anıt da Hatip Su Anıtı'dır. Burada tespit edilen kaya kabartmasında Kurunta adının geçmesinden dolayı Kurunta Anıtı olarak da bilinen bu yapı, bir su kaynağının üzerine inşa edilmiştir. Konya'nın Ereğli ilçesinde de büyük bir kaynağın yanına konumlandırılmış bir anıta rastlanmıştır. Buradaki İvriz Su Anıtı'nda karşımıza çıkan kabartmalarda tanrı Tarhunza ve kral Warpalawa'nın adları geçmektedir. Bu da bu anıtın aynı zamanda bir tapınak olduğunu göstermektedir. Bu yapılardan başka Fraktin, İmamkulu, Taşçı, Hanyeri, Sirkeli ve Hemite su anıtları da önemli örneklerdir.

\section{Sonuç}

Evrenin ya da olguların tamamını veya bir kısmını kendisine araştırma nesnesi olarak seçen ve uyguladığı yöntem ve tekniklerle yasalara ulaşmaya çalışan sistemli bir bilgi kümesi şeklinde tarif edebileceğimiz bilim, insanlık tarihi boyunca büyük aşamalar kaydetmiştir. Toplumsal hayatın bir ürünü olan bilim, hem insanların edimleriyle şekillenen hem de bir arada yaşamayla birlikte toplumları dönüştüren bir yapıya sahiptir. Bu bağlamda belirli bir alana yönelerek elde edilen tutarlı, geçerli ve düzenli bilgi topluluğu, uygarlığın ilerleme düzeyinin de önemli göstergelerinden biridir. Benzer bir durum, öznenin herhangi bir nesneyi pratik amaçları için değiştirmesini içeren teknik bilginin gelişimi için de geçerlidir. Buna koşut olarak Hititlerin de bir uygarlığın tesisi noktasında inşa ettikleri su yapılarıyla yüksek bir seviyeye ulaştıklarını vurgulamak yerinde olacaktır. 
Mezkûr bilgiler 1şığında Anadolu'nun ilk yerleşimcilerinden olan Hititlerin mimari ve mühendislik alanlarında önemli bir düzeye ulaştıklarını ve günümüzde bile kullanılan yapılar oluşturmayı başardıklarını söylemek mümkün gözükmektedir. Hititler, günlük gereksinimlerinin yanında dini inançları çerçevesinde su yapılarını kurmuşlar ve baraj, havuz, anıt gibi birçok örneği bulunan bu yapılar birer tapınak olarak da işlev üstlenmiştir. Burada dikkat çekici bir unsur da suyun toplandiğ 1 bu yerlerden yaşam alanlarına doğru iletiminin sağlandığg kanallardır. Yapılan kazılarda pişmiş topraktan üretilmiş ve iç içe geçirilerek kullanılmış olan silindir boruların tespit edilmesi Hititlerin sahip olduğu bilgi birikimini de ortaya çıkarmaktadır. Hititler, oldukça başarılı bir su sistemi kurmuşlar ve Anadolu coğrafyasının şekillenmesine katkı sağlamışlardır. 


\section{KAYNAKÇA} Yayınları.

AKURGAL, Ekrem (2005). Anadolu Kültür Tarihi, Ankara: TÜBİTAK

ALP, Sedat (2001). Hitit Çağında Anadolu/Çiviyazılı ve Hiyeroglif Yazılı Kaynaklar, Ankara: TÜBİTAK Yayınları.

BİLDİİCİ, Mehmet (2008). "Hitit Öncesi ve Hititler Dönemi Tarihi Su Yapıları", Beşinci Dünya Su Forumu Bölgesel Hazırlık Süreci Türkiye Bölgesel Su Toplantıları Tarihi Su Yapıları Konferansı, ss. 21-28, İzmir: Çevre ve Orman Bakanlığı Yayınları.

ÇINAROĞLU, Aykut ve Duygu ÇELIKK (2006). "2004 Y1lı Alaca Höyük ve Alaca Höyük Hitit Barajı Kazıları", 27. Kazı Sonuçları Toplantısı, Cilt I, ss. 1-6, Ankara: Kültür ve Turizm Bakanlığı Yayınları.

ÇINAROĞLU, Aykut ve Elif GENÇ (2005). "2003 Yılı Alaca Höyük ve Alaca Höyük Hitit Barajı Kazıları”, 26. Kazı Sonuçları Toplantısı, Cilt I, ss. 265-276, Ankara: Kültür ve Turizm Bakanlığı Yayınları.

DE MARTINO, Stefano (2003). Hititler, çev. Erendiz Özbayoğlu, Ankara: Dost Kitabevi Yayınları.

GURNEY, Oliver Robert (2001). Hititler, çev. Pınar Arpaçay, Ankara: Dost Kitabevi Yayınları.

İNAL, İnci (2009). MÖ 1250'den Günümüze Hitit Barajı, Ankara: DSİ Genel Müdürlüğ̈̈ Yayınları.

KINAL, Füruzan (1991). Eski Anadolu Tarihi, Ankara: Türk Tarih Kurumu Yayınları.

MACQUEEN, J. G. (2001). Hititler ve Hitit Çă̆ında Anadolu, çev. Esra Davutoğlu, Ankara: Arkadaş Yayıncılık.

MURAT, Leyla (2012). "Hititlerde Su Kültü”, Tarih Araştırmaları Dergisi, Cilt XXXI, 51: 125-158.

SÜEL, Aygül (2012). "Hititlerde Ceza Hukuku”, Ömer Çapar'a Armă̆an, yay. haz. T. Yiğit, M. A. Kaya ve A. Sina, Ankara: Hel Yayıncılık.

PONTING, Clive (2011). Yeni Bir Bakış Açısıyla Dünya Tarihi, çev. Eşref Bengi Özbilen, İstanbul: Alfa Yayınları. 